\title{
Gender Discrimination against Female Managers and Professionals in Sri Lankan Private Sector
}

\author{
Iromi M. Dharmawardhane ${ }^{1}$, N.N.J. Navaratne ${ }^{2 *}$ \\ ${ }^{1}$ Research Associate, Institute of South Asian Studies, National University of Singapore, SINGAPORE \\ ${ }^{2}$ Senior Lecturer, Department of Human Resources Management, Faculty of Management and Finance, University of Colombo, SRI LANKA \\ "E-mail for correspondence: nimalnawa@hrm.cmb.ac.lk
}

$\underline{\text { https://doi.org/10.18034/abr.v9i2.253 }}$

\begin{abstract}
Gender discrimination and sexual harassment contradict with the rights of women protected by law and practices at private sector organizations in Sri Lanka that may limit the career advancement of female employees. Several empirical researches on gender discrimination confirmed the impact of gender discriminations and sexual harassments on work motivation and productivity. However, this debilitating effect on the motivation and productivity of the female managers and professionals in Sri Lanka has not seen any empirical conclusion. The purpose of this study is to explore the relationship between workplace gender discrimination and sexual harassment with employees works motivation and productivity. The study conducted by selecting 66 female employees (44 female managers/ professionals, $22 \mathrm{HR}$ managers) as a sample from 22 medium and large scale organizations covering the Sri Lankan private sector. Both quantitative and qualitative analyses conduct on collected data through a self-administered questionnaire. The results confirmed the incidents of gender discrimination and sexual harassment are present in recruitment and promotions activities in the selected organizations. However, the results did not support the relationships between gender discrimination and the loss of motivation and productivity at work.
\end{abstract}

Key words: Gender discrimination, Recruitment and Promotion, Sexual harassment, Work motivation, Productivity

\section{INTRODUCTION}

In many countries, gender discrimination and sexual harassment in the labor market limit opportunities for women to obtain well paid work, promotions, and respect from an employer. Gender discrimination involves treating employees or prospective employees differently due to their gender, gender identity, or sexual orientation. These different conducts may occur in the context of hiring, firing, promotion, pay, benefits, or job classifications. The Gallup World Poll (2012) showed that in every region in the world, men were two times more likely to have "good jobs" than women (Marlar and Mendes, 2013). However, gender discriminations and sexual harassment in today's workplace is usually hidden, making it ambiguous and often very difficult to prove.

According to the World Economic Forum Global Gender Gap Report (2017) showed that "Sri Lanka's gender gap increased over the last year and gender equality ranking declined from a 100 in 2016 to 109" in 2017 out of 144 countries, but again rank became 100 in 2018 out of 149 countries. Discrimination of women is widely reported globally in the private sector (International Confederation of Free Trade Unions, 2004). The main deficit in "good jobs" for women is observed in South Asia and non-EU European countries, is more than 20 percentage points lower than for men. According to Alvaredo et al. (2013), the gender dimension has received little attention in the recent literature on top incomes.

This paper looks at the gender discrimination, and sexual harassment occurred in recruitment, promotions, faced by female managers and professionals in Sri Lankan private sector organizations. Research conducted on gender discrimination faced by managers and professional women is very limited in the Sri Lankan context, and suppose that the research findings of this nature will contribute to meeting this research gap. Therefore not many, detailed and empirical studies have been performed to investigate the impact of workplace discrimination and sexual harassment of female managers and professionals of Sri Lanka. 


\section{LITERATURE REVIEWS}

Discrimination can be direct or indirect. Direct discrimination (or disparate treatment) occurs when female employees are treated less favorably than their male counterparts solely on the grounds of gender. Gender based discrimination can include lower pay for equal abilities, discriminatory questions at a job interview, or an employer not hiring, training, promoting or wrongfully terminating an employee based on gender. The research found that women continue to be underrepresented in senior positions worldwide in private sector organizations (International Monetary Fund, 2013). According to Society for Human Resource Management (2018) report $1 / 3$ of executives have changed behaviors at work to avoid any behaviors that could be perceived as sexual harassment yet more than $1 / 3$ of workers still report that their workplace fosters sexual harassment in the United States. Usually, indirect discrimination (or disparate impact) occurs when a company's policies and practices make it difficult for one gender to fulfill job requirements at the workplace. Researchers identified this phenomenon as a glass ceiling as the gender gap and its high in upper-level corporate jobs between men and women (Albrecht et al., 2000). Glass ceiling falls under the category of promotional bias that prevented women from moving up the corporate ladder and this concept birthed in the late 1900s.

Some researchers discuss the glass ceiling in terms of earnings (Arulampalam et al., 2007), that means female earn fewer than men. Some of the findings of the Centre for Women's Research (Jayaweera, 2008) shows that the private sector in Sri Lanka had much fewer women in the highest management levels than in the public sector (Silva, 2013). However, in Sri Lanka, there is legal protection against discrimination at the workplace in the private sector, while the women in the public sector having better protection from adherence to national labor legislation. Wage disparities also exist between men and women in Sri Lanka. Women generally face obstacles in rising to supervisory positions traditionally held by men. But, in spite of all the pressures and legal changes from national and international organizations which have taken place, it is not in doubt that an advancement in the positions held by women in large organizations has been somewhat uneven and slow (Cordano et al., 2002).

Studies revealed that irrespective of the occupation, the perceived lack of skills, family constraints, security issues, work location, and maternity benefits deter active participation of women. One reason for having fewer female managers in the organizations may cause by the less female participation in the economically active workforce of the countries. For example, according to the data only 33.4 percent contributes to the national economy from 8.5 million of the economically active female population in Sri Lanka. The barriers limiting the female labor force participation rate and women in entrepreneurship globally recognized with the many interconnected constraints. For example, less access to education and skills training, lack of access to finance, the non-availability and high cost of child care, household and family responsibilities, legislative barriers, discrimination at the workplace, discriminatory cultural practices, and working conditions not suitable for women (IFC, 2013). Further, Risseeuw (1991) explained that gender discrimination in employment as well as cultural practices including customary law which infringe on the rights of women. Women's family situation, have especially presented obstacles to progression (Kirchmeyer, 2002).

Latest research by the Colombo Stock Exchange (CSE) in 2018, International Finance Corporation found that 8.2 percent of more than 1500 board directors in Colombo Stock Exchange-listed companies were women. According to The Global Gender Gap Report (2013), women constituting only $9 \%$ of the top management position of the organizations.

Research conducted by Gunawardena (2017) shows that there is only a $13.25 \%$ of female participation in the top management positions. The research findings showed that there are $9 \%$ of females in director board, $16 \%$ females in corporate management and $13 \%$ females as the management team. In overall perspective the research highlighted that there are $13 \%$ of female participants in the managerial positions in banks.

The survey done by Kangaraarachi (2011) found that a number of women in senior management positions in large companies was only one female Chief Executive Officer (CEO) in 2009 in the 40 Most Valuable Brands (MVB) of Sri Lanka and among the next 33 companies there were only three female CEOs. Therefore better to assume that the average percentage of women in management in Sri Lankan business organizations but broad estimates would place the figure between 10 to 11 percent of the total cadre. According to the research female employees in senior and middle management positions in Sri Lanka is $24 \%$ and by deducting an average percentage of female top management positions ( $9 \%$ to $10 \%$ ) it can be calculated average female middle management percentage is approximately $15 \%$ to $14 \%$. For example in the garment sector, more than $90 \%$ of employees are female, but in many organizations, no female employee is assigned to a top management position but few in middle management positions. However phenomenon of female employees is underrepresented at senior levels of the management hierarchy is common situation in the world. Women are generally viewed negatively by employer in Sri Lanka due to most of them not being able to work for long hours and their requests for parental leave (Shyamala, 2011; Bombuwela et al., 2013) or due to lack of self-confidence to them. 


\section{Gender Discrimination and Sexual Harassment in Sri Lanka}

A Joint study between the International Labor Organization (ILO) and Employers' Federations of Ceylon (EFC) shed light on types of gender discrimination faced by Sri Lankan women in the workplace. A significant study conducted by a team led by Gunewardena (2012) found that differences in wages are much higher between women and men than what was previous statistics indicated. The wage gap between similar males and females at the bottom end of the wage spectrum can be as large as 33\% in the private sector and $27 \%$ in the public sector. Wage gaps at the top end of the spectrum are considerably smaller in the public sector at around 5-6\%, but remain high in the private sector, at about $20 \%$. There is a significant wage gaps between men and women at the bottom end of the labor market. This gap is very wide between male and female employees in the informal sector than the formal one.

Research data also implies that women are working within a limited range of occupations and industries where their characteristics are rewarded better, such as teaching, nursing or the garment sector. Arun and Borooah (2011) study entitled "The Gender impact in Earnings Inequality: Evidence from Sri Lanka" concluded that gender disparity irrespective of their "inferior" labor market attributes, men had average earnings that were considerably higher than the female average and that this could be attributed entirely to discrimination in favor of male earners.

Section 345 of the Sri Lankan Penal Code as amended in 1995, defines sexual harassment as "unwelcome sexual advances by words or actions used by a person in authority in a working place or any other place." The definition given by the International Labor Organization (ILO) is that "sexual harassment comprises unnecessary physical contact; touching and patting; suggestive or unwelcome remarks, vulgar or crude jokes; deliberate verbal abuse, leering; suggestive invitations; display of pornographic pictures; and demanding sexual favors." Sri Lanka consists of paradoxes in terms of gender equality (Jayawardena, 2005) while having some of the highest ratings in Asia and the world in some service areas including health and education.

There are widespread complaints of sexual harassment of women in the workplace in Sri Lanka, although recognition of its existence and measures to fight it have been low at the state level and within the public and private sectors (Balachandran, 2012). It receives on average of ten complaints of sexual harassment daily with the sending of sexually explicit text messages being the most common form of sexual harassment. In the 80 cases of sexual harassment from the financial sector, unwanted sexual comments were the most prevalent (21 cases), followed by unwanted looking and staring came next (14 cases), suggestive jokes (12 cases), displaying sexist material (10 cases). There were also two cases of punishing a female employee for denial of sexual favors or rewarding her for granting it (Balachandran, 2012). A study was undertaken by Adikaram (2005) clearly shows that sexual harassment was widespread in the financial sector. Researchers found that in the United States, sexual harassment can negatively impudence women's career trajectories (McLaughlin et al., 2017).

Impact of Gender Discrimination \& Sexual Harassment on Female Employees Work Motivation and Productivity

Both direct and indirect discriminations influence employees' motivation and motivation influence on performance. Wright and Boswell (2002) have argued "any research needs to demonstrate a relationship between HRM and firm performance stands on firmer ground when assessing actual practices of the organization rather than the intended policies. Motivation in contemporary psychology encompasses three main problems such as drive, goal direction or purpose, pleasure and pain or nature of reinforces. Gender discrimination turns the employees' emotionally brittle; simple peace-loving employees transform into paranoid and suspicious, fearful and angry individuals. This link presents following Figure 1.

Figure 1: Practices versus outcomes

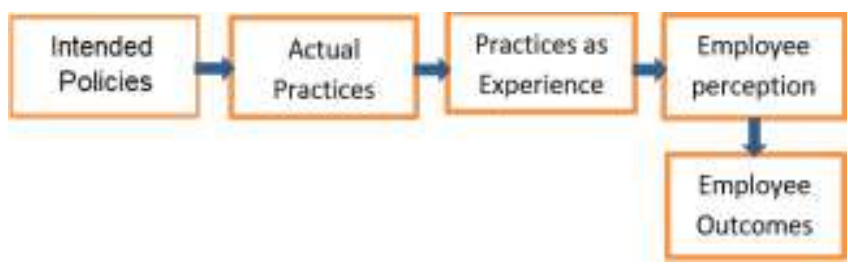

Source: Authors

Bennington's study (2006) found that significantly less female line managers involve in making decisions based on of unlawful questions than male managers. Thus, the study points out female line managers as guardians of Equal Employment Opportunity (EEO), but it does not indicate that HRM plays this role as expected. In the study on sexual harassment undertaken by Adikaram et al., (2011) found that in the case of many victims, the emotional stress created by sexual harassment had directly affected their work. Strategic Human Resource Management (SHRM, 2018) revealed that following impact (Table 1) of sexual harassment of the employees by asking the question "What has been the impact of sexual harassment on your organization?" from 337 female executives.

Table 1: Impact of sexual harassment

\begin{tabular}{|l|c|}
\hline & Executives \\
\hline Decreased Morale & $23 \%$ \\
\hline Decreased Engagement & $23 \%$ \\
\hline Decreased Productivity & $18 \%$ \\
\hline Increased Hostile Work Environment & $15 \%$ \\
\hline Increased Turnover & $13 \%$ \\
\hline
\end{tabular}

Stella and Goodfaith (2016) found that there is a relationship between company culture and gender inequality on the corporate performance. Moreover, this 
study found that company culture regarding recruitment and promotion, career development, training and mentoring was positively related to corporate performance of the banking sector. Employee productivity is the efficiency of the workforce measured by the output of their work during a given time period.

Mhlanga's (2016) study showed that extrinsic motivation given to health care workers has a significant influence on worker performance and that a relationship exists between employee motivation and organizational performance. Chaudhary and Sharma (2012), show that employee motivation has a direct impact on productivity and growth. However, according to Wentzel and Wigfield (2009), the relationship between employee motivation and productivity is not positively established.

Alshatti et al., (2011) found that gender discrimination in hiring, gender biasness in promotion and gender disparity in provision of goods and facilities have negative relationship with productivity. Research conducted by Soomo et al., (2015) have concluded that gender discrimination factors are not much contributing toward employee performance but discrimination in promotion positively related with employee performance. Channar et al., (2011) research shows that gender discrimination decreases satisfaction \& motivation and commitment \& enthusiasm level of employees, and increases the stress level in the employees.

\section{Research Methodology and Design}

\section{Research Problem}

As discussed above there is also an extensive inconsistency between the rights of women protected by law and the daily life in and practices of private organizations in Sri Lanka. Also, although gender discrimination and sexual harassment against female employees in employment widely reported in Sri Lanka, there is still no government body to practice and monitor the implementation of fair employment practices in the private sector organizations. Elimination of gender discrimination is crucial for the motivation and productivity of female employees. Therefore, the main research issue of the study is to explore the relationship between gender discrimination and sexual harassment in recruitment, promotions with motivation and productivity of female managers and professionals in private sector organizations in Sri Lanka.

\section{Research Questions}

1. Do gender discrimination and sexual harassment on female managers and professionals prevail in the areas of recruitment and promotions in Sri Lankan private sector organizations?

2. What is the relationship between gender discrimination and sexual harassment with motivation and productivity of female managers and professionals in Sri Lankan' private sector organizations?
In conducting this study the survey method is employed to collect required data from 66 female employees (44 female managers/ professionals, 22 HR managers) from 22 medium and large organizations from Sri Lankan private sector organizations. This study was conducted mainly by primary research data in collecting through a structured questionnaire in the form yes or no, multiple choice, and scale questions and open-ended questions, and mix method used to analyze the collected data.

\section{Research Objectives}

There are two research objectives pursued by this study.

- To identify gender discrimination and sexual harassment of female managers and professionals in the areas of recruitment and promotions among managerial and professional positions in Sri Lankan private sector organizations.

- To explore the relationship between gender discrimination and sexual harassment with motivation and productivity of female managers and professionals in Sri Lankan private sector organizations.

Two hypotheses developed about the expected objectives of the study.

$\mathrm{H}_{1}$ : Gender discrimination and sexual harassment in recruitment and promotions exist among managerial and professional positions in Sri Lankan private sector organizations.

$\mathrm{H}_{2}$ : Gender Discrimination and sexual harassment reduce motivation and productivity of female managers and professionals among managerial and professional positions in Sri Lankan private sector organizations.

\section{Data Collection Method}

A self-administered questionnaire used as the research instrument. Questions were mostly quantitative, close-ended with Yes/No, True/False, multiple choice, attitudinal scale (seven-point numerical scale) questions. Two different questionnaires, one for female managers / professionals and one for HRM personnel, were completed by three respondents from each organization - two respondents being female managers/ professionals and one respondent being a senior human resources manager/ director. Selected sample of 22 medium and large size organizations are ten (10) service/ distribution companies, six (6) manufacturing/ processed food production/ construction companies, four (4) agriculture companies, and two (2) diversified companies. Eight (8) questionnaires not returned by the respondent and then final sample became 58 respondents ( 37 female managers / professionals, $21 \mathrm{HR}$ managers).

\section{Data Analysis}

Quantitative data analysis was conducted using IBM's Statistical Package for the Social Sciences (SPSS) version 16 computer software, while the opened ended questions analyzed by the researcher, and then cross-analyzed. The 
qualitative data analyzed included details of incidents of gender discrimination or comments on how gender equity achieved in an organization. When conducting the quantitative analyses using SPSS, descriptive statistics were used to identify the mean, mode, frequency tables, and percentages.

\section{Results AND ANALYSIS}

Out of 37 female managers and professionals, 35 respondents of the survey $(85.7 \%)$ believed that there was no gender discrimination in the recruitment process between men and women were treated equally while $2.9 \%$ and $11.4 \%$ men and female assumed there was gender discrimination respectively. For gender discrimination about promotions, $85.3 \%$ male and female employees perceived equal promotion opportunities, while $2.9 \%$ and $11.8 \%$ said that male and female employees were discriminated against in promotions respectively.

Table 2: Valid Percentage of Employees Gender discrimination on Recruitment and Promotion

\begin{tabular}{|c|c|c|c|}
\hline \multicolumn{1}{|c|}{ Valid } & Frequency & Recruitment & Promotion \\
\hline No Gender Discrimination & 30 & $85.7 \%$ & $85.3 \%$ \\
\hline Male Discrimination & 01 & $2.9 \%$ & $2.9 \%$ \\
\hline Female Discrimination & 04 & $11.4 \%$ & $11.8 \%$ \\
\hline Total & 35 & $100 \%$ & $100 \%$ \\
\hline
\end{tabular}

Source: Research Data

Further, the research found that $77.8 \%$ of the female managers/ professionals believed that they could reach the top senior management level in their organizations while $22.2 \%$ of female managers/professionals perceived that they failed to reach the higher potion of the management. Result of the research not marginally support the previous research findings (Albrecht et al., 2000; Arulampalam et al. 2007; Gunawardena, 2017) that glass ceiling falls under the category of promotional bias that prevented women from moving up.

Table 3: Female Employees Possibility to get a position in Senior Management

\begin{tabular}{|c|c|c|}
\hline & Frequency & Valid \% \\
\hline Valid No & 8 & 22.2 \\
\hline Yes & 28 & 77.8 \\
\hline Total & 36 & 100 \\
\hline
\end{tabular}

Source: Research Data

Types of incidents of gender discrimination related to promotions given by respondents (female managers) include:

- Male employees in the same division getting promoted over a female although she worked harder than them.

- Not promoted due to being newly married and the possibility of being away from work due to conceiving.

- Men promoted more due to longer work hours (2 respondents).
From the participants, $94.6 \%$ said that they would feel comfortable telling their immediate supervisor or the HR department if they subjected to gender discrimination concerning promotions or sexual harassment. Of those who had reported their issue to the organization, 24.3\% said that they were "satisfied with the way the issue was handled and resolved."

\section{Sexual Harassment}

Table 4 shows the percentage of the managers and professionals experience on male and female sexual harassment in their organizations. Out of total respondents $(\mathrm{N} .28), 62.2 \%$ said that neither men nor women subjected to sexual harassment. However, 13.5\% said that women suffered sexual harassment in the organizations that they worked.

Table 4: Experience on male and female Sexual harassment

\begin{tabular}{|l|c|c|c|c|}
\hline & Frequency & $\%$ & Valid \% & Cumulative \% \\
\hline Valid Equal & 23 & 62.2 & 82.1 & 82.1 \\
\hline Women Discriminated & 5 & 13.5 & 17.9 & 100 \\
\hline Total & 28 & 75.7 & & \\
\hline Missing & 9 & 24.3 & & \\
\hline
\end{tabular}

Source: Research Data

But the question No. 5 asked from female employees in the occupational group of managers and professionals to understand their sexual harassment. A higher percentage of sexual harassment came out when analyzing the number of respondents who had themselves suffered sexual harassment or knew others in the organization that exposed to sexual harassment; $27 \%$ of the respondents reported that they mistreated by doing sexual harassment in their organizations and $18.9 \%$ of respondents were aware of another female manager/ professional who had sexually harassment.

Table 5: Recalled Percentage of Sexual Harassment

\begin{tabular}{|l|c|c|c|}
\hline & Frequency & Valid \% & Cumulative \% \\
\hline Valid Equal & 27 & 73.0 & 73.0 \\
\hline Women Discriminated & 10 & 27.0 & 100 \\
\hline Total & 37 & & \\
\hline
\end{tabular}

Source: Research Data

The discrepancy could be due to respondents being reluctant to generalize their experience of sexual harassment as more widely prevalent in the company. The combined percentage of respondents who have been sexually harassed or knew others who did were $45.9 \%$ which is nearly half of the respondents. There is also the possibility that those who had suffered sexual harassment to say that another was sexual harassed (instead of saying that they were) due to the social stigma attached to and personal nature of the issue as well.

Types of incidents of sexual harassment given as examples by the respondents (female managers) include:

- Comments and staring, and when confronted, were passed as jokes not to be taken seriously.

- A boss trying to be too close to an employee physically. 
- Deliberate touching, seemingly accidental touching, displaying of pornography by the head of department and managers.

- Sexual jokes between [work] friends.

- Remarks about my attire and my dancing (I am a professional dancer); male colleagues putting their arm around my shoulders.

- A practical joke which extended beyond its limits of good humor, sexually harassing a co-worker.

- I was asked by a colleague if he can have sex with me.

\section{HR Managers Perception of Gender Discrimination}

One of the Chairman and HR Director was convinced and over-confident that their present system of emotional intelligence based employment/ recruitment policy and the company's code of ethics protect discrimination against women. While reporting an average of zero incidents of sexual harassment cases and gender discrimination with relation to promotions, the Chairman/ HR Director stated that "we practice emotional intelligence based employment (recruitment) policy and the company has its code of ethics in corporate governance such that the issue of affirmative action does not arise." However, one of the female managers said about promotions that: "men get priority, [because] women are not demanding." She also believed that due to her gender there was no possibility of reaching the top level of management stating that, "my company will not offer a top management post for a lady."

To the question of whether recruitment ads were neutral in terms of gender, $81 \%$ of the companies HR managers said that they carried gender-neutral ads, while $21 \%$ said they were not. For the $21 \%$ of organization thought a certain genders were better for different kinds of jobs in the organization so ads are not neutral. From the 21 organizations, HRM personnel $81 \%$ (17 organizations) reported that marital status was asked during recruitment of women by the HR Manager/ Director or CEO or by other senior manager during the interview process. Of the 37 female managers/ professionals, $51.4 \%$ stated that they were asked their marital status in their job interview. It also revealed that $62.2 \%$ of the respondents were single at the time of recruitment, which suggests an employer's preference to hire single females.

One HR Manager in a service sector company revealed that gender-based recruitment is fair as, "to market certain products such as machines and for jobs that involve extensive traveling, males are preferred." And this was apparent in the total numbers of employees as well; the company had a male population which was near than double of female population. A Director of Trading in another organization from the service sector said that "due to long work hours and extensive traveling, males get priority over females for certain jobs." In both these cases, there is an internally placed system of occupational segregation for men and women, which is a gender discriminatory practice which affects recruitment as well as promotions.
Another HR Manager of Group Communications and Corporate Marketing in a service sector firm said that "a lot of external factors come into play when evaluating women as opposed to men." Another Manager in the service sector said that for promotions, "men get priority, [because] women are not demanding." She also believed that due to her gender there was no possibility of reaching the top level of management stating that, "my company will not offer a top management post for a lady. A product designer in service sector company commented that "men tend to get promotions quickly as they work long hours, while female employees unable to work long hours due to family responsibilities." She added that. "When the manager is male, he tends to support male employees [under him] more due to their ability to work longer hours and because it is easy for him to get along with them than a lady." [Language slightly edited] A Senior Analyst from a different service sector firm agreed: "If it's a job requiring long hours, women usually overlooked as most women and, their families perceived as not liking to work late."

One Manager of Talent Resourcing/ Acting Head of HR in service Sector Company believed that their diversity policy prevents gender discrimination and the records are that there have been zero incidents of sexual harassment and gender discrimination. But, one of the female managers interviewed said: A manager of group communications and corporate marketing in a service sector stated that, "females perceived as provocateurs of acts of sexual harassment [by men], and this is partly due to stereotyping and male dominance." She also said that women were discriminated against when it comes to promotions and that, "a lot of external factors come into play when evaluating women as opposed to men." Both this manager and the other product manager informed sexually harassed.

One of the HR managers in the service sector said his company has a gender equity policy covering recruitment, pay, performance appraisals, promotions, parental leave, and sexual harassment and claims zero incidents in both on average. However one of the professionals not reported sexual harassment. The other stated gender discrimination about promotions.

\section{Impact of Gender Discrimination and Sexual Harassment on Work Motivation and Productivity}

Impact of gender discrimination on work motivation and productivity were to be found out from the relevant responses given by the female managers/ professionals, as the victims would be better at determining this and others would generally be unaware of the effects, especially in terms of work motivation. Of the 37 female managers/ professionals, only one respondent $(2.7 \%)$ reported that she had "trouble concentrating/ being productive at work as a result of being discriminated against based on gender about promotions at work," and that she could not concentrate and be productive at work for some hours. This female manager/ 
professional did not let her ability to concentrate or productivity at work suffer because "maintain a working relationship" with her superiors. There was another female manager/ professional who believed that having suffered gender discrimination compelled her to "work harder and become more productive than before." From the participants, $94.6 \%$ said that they would feel comfortable telling their immediate supervisor or the HR department if they were subject to gender discrimination concerning promotions or sexual harassment. Of those who had reported their issue to the organization, $24.3 \%$ said that they were "satisfied with the way the issue handled and resolved." Similar research results are reported by Wentzel and Wigfield in 2009.

Table 6: Impact of sexual harassment on Motivation and Productivity

\begin{tabular}{|l|c|c|c|}
\hline & Frequency & $\%$ & Valid \% \\
\hline Valid Yes & 1 & 2.7 & 2.7 \\
\hline Missing & 36 & 97.3 & 100 \\
\hline Total & 37 & & \\
\hline
\end{tabular}

Source: Research Data

\section{Policy Implications}

There are several implications of this research to senior management and human resources directors/ managers who are in a position in organizations to adopt measures to prevent negative gender discrimination of women. One implication of the research is that the younger, unmarried women who are recruited into organizations are more likely to become victims of sexual harassment as of them were not married. Further, as suggested by several of the female managers/ professionals who participated in the research study, sexual harassment awareness programs must be carried out in organizations so that female employees are empowered. As Research Objective 2 could not be achieved, further research can be conducted to establish a relationship between (gender) discrimination and loss of motivation as supported by other research conducted previously. However, management should address the issues of gender discrimination and sexual harassment more enthusiastically in their policies such as recruitment and promotion activities to increase employee performance subsequently achieve mission of the organization. Other than Sri Lanka, majority of the Asian countries may have gender base discrimination and work place sexual harassment. Thus, policy makers need to take these issues seriously by creating an environment to prevent and come forward and make complaints when any gender encountered discrimination and sexually harassment than they on deaf ears.

\section{CONCLUSION}

Collected data of this study confirmed that the existence of incidents of gender discrimination and sexual harassment in the areas of recruitment, promotions of female employees holding managerial and professional positions in the selected Sri Lankan private sector organizations. Thus, it can conclude that gender discrimination and sexual harassment in recruitment and promotions of women is likely to exist in many Sri Lankan private sector organizations. However, hypothesis 2 did not support as the research expected to confirm that gender discrimination in recruitment and promotions or sexual harassment adversely affects the motivation level of female managers / professionals which results in a loss of productivity at work. Further research is required to establish the possible correlation between gender discrimination and loss of motivation which caused to unfavorable outcomes of the female employees.

To support the basis for the adoption of gender equity policies in private sector organizations, further research can do in the same areas of recruitment, promotions, and sexual harassment using a larger sample which would give more conclusive and convincing results. Research objective 2 could not be achieved; further research can be conducted to establish a relationship between (gender) discrimination and loss of motivation as supported by other research conducted previously.

\section{REFERENCES}

Adikaram, A.S. (2005) "Sexual Harassment among Women in the Banking Sector in Sri Lanka," Friedrich Ebert Stiftung Regional Cooperation in Asia and Sri Lanka Foundation, Colombo.

Adikaram, A.S., Gunewardena, C., \& Perera, T. (2011). “Sexual Harassment in the Workplace: The Effect of Perpetrator Attributes and Recipient Attributes," Sri Lankan Journal of Management, $16,(3 \& 4)$, pp 63-88.

Albrecht, J., Björklund, A., \& Vroman, S. (2000). "Is There a Glass Ceiling in Sweden?"

http://www2.aueb.gr/conferences/espe2001/pdf/Vroma n\%20S.,\%20Bjorklund\%20A.,\%20Albrecht\%20J..PDF

Alshatti, A.Q, Hameed A, \& Waheed A. (2011) “Gender Discrimination $\mathcal{E}$ Its Effect on Employee Performance/Productivity," International Journal of Humanities and Social Science Vol. 1 No. 15 Special Issue.pp.170-176

Alvaredo, F., Atkinson, A. B., Piketty, T., \& Saez, E. (2013). "The top 1 Percent in International and Historical Perspective," Journal of Economic Perspectives, Vol. 27(3): pp3-20.

Arulampalam, W., Booth, A. L., \& Bryan, M. L. (2007). "Is there a glass ceiling over Europe? Exploring the Gender Pay Gap across the Wage Distribution," Industrial and Labor Relations Review, Vol 60 (2): pp163-186.

Arun, T. \& Borooah, V. K. (2011). "The Gender Impact in Earnings Inequality: Evidence from Sri Lanka," International Journal of Economic Sciences and Applied Research, 4 (2): 71-80.

Balachandran, P. K. (2012). "Recognizing Sexual Harassment in Sri Lanka," Ceylon Today, November 28, 2012, http://www.ceylontoday.lk/59-18201-news-detailrecognizing-sexual-harassment-in-sri-lanka.html, accessed 15 May 2013.

Bennington, L. (2006). "HRM Role in EEO: Sheep in Shepherd's Clothing?," Journal of Business Ethics, 65(1): 13-21, Springer, http://www.jstor.org/stable/25123767, accessed 5 August 2011 
Bombuwela P. M., De Alwis A. Chamaru (2013). "Effects of Glass Ceiling on Women Career Development in Private Sector Organizations - Case of Sri Lanka," Journal of Competitiveness, Vol. 5, Issue 2, pp. 3-19

Channar, Z.A., Abbassi, Z and Ujan I.A. (2011). "Gender Discrimination in Workforce and its Impact on the Employees," Pakistan Journal of Commerce and Social Science, Vol.5 (1), pp.171-191.

Chaudhary, N., \& Sharma, B. (2012). "Impact of Employee Motivation on Performance (Productivity) In Private Organization," International Journal of Business Trends and Technology- volume 2 Issue 4 - (p. 29-35)

Cordano, M., Scherer, R. F., \& Owen, C. L. (2002). Attitudes toward women as managers: sex versus culture, Women, Management Review, 17(2), 51-60.

Gunawardana, K. (2017). Women Participation in senior management positions in licensed commercial banks in Sri Lanka https://papers.ssrn.com/sol3/papers.cfm?abstract_ id=2932679http: / / doi.org/10.4038/sljss.v31i1-2.5464

Gunawardena, M. (2012). What Glass Ceiling? Colombo: Bay Owl Press

IFC (2013) Assessing Private Sector Contributions to Job Creation and Poverty Reduction: Findings on Gender, IFC Jobs Study: January 2013,http://www.ifc.org/wps/wcm/connect/Topics_Ext _Content/IFC_External_Corporate_Site/IDG_Home/JobC reation, accessed 15 May, 2013.

IMF (2013) "Women, Work, and the Economy: Macroeconomic Gains from Gender Equity," IMF Staff Discussion Note, International Monetary Fund (IMF), September 2013 (SDN/13/10).

International Confederation of Free Trade Unions (2004) “Report for the WTO General Council Review of Trade Policies of Sri Lanka," Geneva, 3 - 5 March 2004, http://www.icftu.org/www/pdf/srilankaclsreport2004.p df, accessed 19 June 2011

Jayawardena, K. (2005). "The Paradox Island" in Marina Perera and Rasika Chandrasekera (eds), Excluding Women: The Struggle for Women's Political Participation in Sri Lanka, Colombo: Social Scientists' Association.

Jayaweera, S. (2008) Chandra Gunawardena and Indika Edirisinghe (CENWOR, 2008). "Beyond the Glass Ceiling: Participation in Decision Making in the Public Domain."

Kangaraarachchi, R. (2011). "Less Women in Senior Management Positions," Daily News, 28th February, http:/ /www.dailynews.lk/2011/02/28/bus02.a sp, accessed 14 March 2011.

Kirchmeyer, C. (2002) “Gender Differences in Managerial Careers: Yesterday, Today, and Tomorrow, " Journal of Business Ethics, 37(1):5-24.
Marlar, J. \& Mendes, E. (2013). “Globally, Men Twice as Likely as Women to Have a Good Job, Women's deficit in the "good jobs" market is biggest in South Asia," GALLUP, September 27th, https:// news.gallup.com/poll/164666/globallymen-twice-likely-women-good-job.aspx.

McLaughlin, H., Uggen, C., \& Blackstone A. (2017). "The Economic and Career Effects of Sexual Harassment on Working Women." Gender and Society 31 (3).

Mhlanga, M. P. (2016). “The Impact of Workplace Motivation on Employee Performance within the Ministry of Health in Swaziland," Texila International Journal of Management Volume 2, Issue 2

Ortiz-Ospina, Esteban and Roser, Max (2018). Economic inequality by gender, Our World in Data, https://ourworldindata.org/economic-inequalityby-gender

Risseeuw, C. (1991) "Transformation in Women's Access to Land and Property," Gender Transformation, Power and Resistance among Women in Sri Lanka, Manohar: New Delhi.

Shyamala, G. (2011). Gender Advisor at the United Nations in Sri Lanka in Daily News,

Silva, K.T., 2013. Beyond the glass ceiling: participation in decision making in the public domain by Swarna Jayaweera, Chandra Gunawardena and Indika Edirisinghe (CENWOR, 2008). Sri Lanka Journal of Social Sciences, 31(1-2), pp.65-67.

Society for Human Resource Management (2018). https://www.shrm.org/about-shrm/press-room/pressreleases/pages/sexual-harassment-survey.aspx

Soomo P., Soomro F., Menmon M.S. (2015). "Gender Discrimination and its Impact on Employee Productivity/Performance" (A study on government universities of upper Sindh), International Journal of Management Science and Business Resreach, Vol 4 Issue 6, pp.36-40

Stella, M. I. \& Goodfaith, O. (2016). "Effect of Gender Inequality on Corporate Performance - A Study of selected Banks in South East, Nigeria," Advanced Research Journal of Multi-Disciplinary Discoveries August/Vol.4.0/Issue-I

The Global Gender Gap Report 2013. Switzerland: World Economic Forum

The Global Gender Gap Report 2017. Switzerland: World Economic Forum.

The Global Gender Gap Report 2018. Switzerland: World Economic Forum.

Wentzel, K.R., \& Wigfield, A. (2009). Handbook of Motivation at School Routledge, New York.

Wright, P. \& Boswell, W. (2002). “Desegregating HRM: a review and synthesis of micro and macro Human Resource Management Research, “Journal of Management, 28:3, 247-276 A. S. (2015).

$--0--$ 